\title{
LOURENÇO: JOGRAL IMPERTINENTE
}

\author{
Affonso Robl \\ Universidade Federal do Paraná
}

\begin{abstract}
RESUMO
O autor procura precisar as atribuiçōes a a condiçāo do jogral na sociedade hierarquizada da Península Ibérica do séc. XIII. O jogral é o profissional que vive do seu mister: citolar e dizer sões alheios; um homem, portanto, que pertencc à classe servil. A jogralia, palaciana ou popular, era, pois, ofício próprio do vilāo; ciaí, a incompatibilidade, ao menos teórica, que na Peninsula havia entre a condição nobre e a profissāo jogralesca. Embora congregados pelo mesmo objetivo - proporcionar entretcnimento aos fidalgos - existia entre as classes trovadorescas das cortes e solares certo clima de tensōes e conflitos, provocado pelo fato incontrolável da ascensāo social por parte de jograis talentosos, peritos na arte de trobar.

Apesar de sua origem humilde, Lourenço tornou-se o melhor dos jograis-poetas. Mas seu talento e sua ambiçāo chamaram a atenção dos trovadores de cstirpe, que mote jam de suas pretensōes trovadorescas, taxando-o de incompetente. Em contrapartida, Lourenço, fecundo tencista, revida bravamente aos ataques dos artistas de mais elevada linhagem.

Lourenço, protótipo do jogral com pretensōes a tro. vador, conseguiu atingir, por suas qualidades artísticas c por sua pertinácia e impertinência, posição de relevo no trovadorismo galego-português.
\end{abstract}

Personagem interessante e original, o jogral Lourenço atraiu a atenção de vários estudiosos: Carolina Michaëlis de Vasconcelos, Menéndez Pidal, José Joaquim Nunes, Antônio José Saraiva, Rodrigues Lapa e, sobretudo, Giuseppe Tavani. ${ }^{1}$

A mingua de outras fontes, os lineamentos do perfil hu. mano, do caráter e da dimensāo histórica de Lourenço devem

1 Ver a respectiva bibllografia. 
ser deduzidos de sua própria obra literária e de poesias que a ele se referem. Conhecemos, porém, o risco que se corre quando se trabalha sobre textos poéticos, pois não nos esquece a frase lapidar de Fernando Pessoa. Mas, embora os poetas medievais também finjam "que é dor a dor que deveras sentem"; embora as rigidas regras da poética trovadoresca condicionem, de certa forma, a emotividade e a liberdade de expressão, é preciso acreditar que existem rios subterrâneos que acabam sempre for aflorar."

A reconstituição da personalidade de um autor torna-se mais insegura e movediça quando está baseada em cantigas d'amigo, nas quais o poeta esconde por detrás de tópoi subrepticios a sua realidade humana. Já nas cantigas d'escárnio e maldizer, e nas tensões, o tom polémico costuma revelar um pouco mais nitidamente - em que pese às evidentes hipérboles - a verdade dos fatos, não pretendendo com isso dizer que tudo se deva tomar ao pé da letra, quase como se fossem crônicas versificadas.

O que importa frisar é que as poesias satíricas e polêmicas são, ao que se supõe, provocadas por fatos ou motivos reais. Por isso, não conseguimos concordar com Eugênio Asensio, para quem as burlas medievais não podem ser consideradas como fonte segura de informações, visto que "el Pegaso de los poetas satíricos, cansado muy pronto de pacer en los prados de la realidad, propende a remontarse a las nubes de la imaginación o convención". ${ }^{3}$ Embasada na vida real e não no mundo dos sonhos, a sátira, além de refletir a sensibilidade e a criatividade do autor, não deixa de conter, descontadas as hiperbólicas fórmulas tópicas, algum material biográfico, constituindo assim valioso documento de informação.

\section{Lourenço era jogral}

E incontestável que Lourenço foi jogral. Este fato vem atestado pelas rubricas dos cancioneiros e confirmado pelos interlocutores nas composiçōes polêmico-satíricas. O Cancioneiro da Biblioteca Nacional (CNB) e 0 Cancloneiro da Biblioteca Vaticana (CV) atribuem a "Lourenço jograr" um total de dezoito composições, das quais sete, que são tençōes, vêm transcritas unicamente no $\mathbf{C V}$ e as demais, em ambos os apógrafos italianos; trata-se de duas cantigas d'amor, sete cantigas d'amigo, uma cantiga de maldizer e oito tençōes.

2 Cr. ADragio, José V. Cantigas de escárnio e maldizer: uma leitura socjolingilistica. Comuniceç⿰丿丶⿸⿴巳一丶 Romanlcas. R!o de Janelro, 1977. Datllografado.

3 ABENBIO, Eugênio. Poética y realidad en el cancienoiro peninsular de la Edad Media. 2.ed. Madrid, Gredos, 1970. p. 125. 
Origina-se o termo provençal jograr do adjetivo latino iocularis ("risivel", "ridículo"), que, substantivado, equipara-se, clesde o séc. VII, a ioculator ("zombeteiro"; "histrião"; "jogral"), para vulgarizar-se, no séc. XII, com a acepção de individuo que diverte tanto a nobreza como a vilania. A forma arcaica, registrada nos cancioneiros, livros de linhagem e documentos legislativos, é jograr, que, mediante dissimilação (cp. fror-frol), passou a jogral.

Equivaliam os jograis aos comediantes latinos (mimi, histriones, scurrae, thymelici) e aos scopas germânicos, isto é, aedos, que, viajando de palácio em palácio, cantavam, como autores ou meros executantes, as gestas da nobreza bárbara.

"Jograis - para Menéndez Pidal - eram todos aqueles que ganhavam a vida atuando perante um público, para recreá-lo com a música, com a literatura, com charlatanices ou com prestidigitações, acrobacias e mimicas."

O certo é que a joglaria era bem mais antiga que o tro. vadorismo. Mesmo antes da época trovadoresca, na Península Ibérica, como também em outras regiōes, o jogral era figura obrigatória em todos os festejos. Disso existem testemunhos nos tempos de Afonso II de Aragão (1180). Jograis e segréis - que representavam a pristina cultura popular da Peninsula, máxime da Galiza - historicamente precedem os trovadores. $O$ jogral, além de executante, podia ser também autor. Por exemplo, o clérigo Gonçalo de Berceo denominava-se jogral de São Domingos de Silos, pois pusera em versos a biografia desse santo.

No séc. XI, surge nova designação occitânica para o poeta-músico: trobador. $\mathbf{E}$ da Provença, que vivia um período de quase dois séculos de paz, vieram os trovadores, com sua arte refinada, ensinar a gente luso-galega "en maneira de provençal a fazer agora un cantar d'amor". Dentre os mestres da poesia galego-portuguesa devem ser ressaltados:

"O jogral Palha, muito considerado na corte de Afonso VII de Castela, burguês de Compostela, mestre da primitiva poesia galega, hoje perdida; o trovador provençal Marcabru, que pregou aos franceses a cruzada contra os mouros e gozou também algum tempo o favor da corte de Afonso VII; e o trovador provençal Gavaudan, o Velho, em cujas composiçōes se encontram referências a Portugal." "

4 MFNendez PIDAl. R. Poesia juglaresca y juglares. Buenos Alres. Espasa-Calpe. 1842. D. 12.

5 LACERDA. V. Cortes. Unidades literárias. Rio de Janeiro, Ore. Bimס́s, 1953. p. 75. 
Mas, quando se uniram o lirismo de inspiração provençal e de origem peninsular, formando aquele equilíbrio interente a toda arte, a poesia galego-portuguesa, que mergu. tha suas raizes na cultura religioso-popular irradiada de Santiago de Compostela, tornou-se mais complexa e, consequientemente, aumentaram as classes ligadas à arte poético-musical: trovadores, segréis, jograis, soldadeiras.

Na Declaratio del senher rey N'Amfos de Castela, de 1275, observa-se o zelo, exagerado, de Afonso X, assessorado por Guiraut Riquier, em fixar com exatidão, para pôr ordem na confusão reinante, os limites entre as diversas classes da hierarquia trovadoresca. ${ }^{6}$ Diligentemente distingue o Rei Sábio os cazurros e os juglares. Os primeiros seriam aqueles que, desprovidos de boas maneiras, recitam sem sentido ou exercem a sua arte vil por ruas e praças, ganhando desonradamente o dinheiro; o rei de Castela também inclui nesta ínfima categoria o bobo da corte (maninelo, bufão ou truão). Carolina Michaëlis apresenta-nos esta idéia sobre o cazurro ou jogral do povo:

"O pultriqueiro que vil e desonestamente exercia o seu mester, isto é, ganhando dinheiro, pouco e mal, nas praças e tabernas, fazendo saltar macaquinhos, cabritos, perros, representando com títeres, remedando vozes de pássaros e dizendo disparates com palavrões para regozijo da arraia miúda":

Os juglares são os que, com cortesia e ciência, sabem comportar-se entre pessoas nobres e ricas, para tocar instrumentos, trazer noticias, contar relatos poéticos, e cantar versos e cantigas feitas por outros. Somente a estes, os jograis da corte, outorga o Rei o direito de se apresentarem nos palácios e solares.

As cantigas d'escárnio e maldizer atestam que as principais atribuiçōes dos jograis eram cantar versos alheios e/ou acompanhá-los com instrumentos de sopro, de corda ou de percussão. Em principio, portanto, entre os galegoportugueses o trovador compunha a palavra e o son das canções que o jogral devia executar. Todavia, essa distinção não é fundamental, porque diversos jograis eram também autores e, em contrapartida, trovadores havia que também executavam composições alheias. O jogral, numa distinção específica, é o profissional que vive única e exclusivamente do seu mister; um homem, portanto, que pertence à classe

6 MENENDEZ TIDNL. op. cit.. p. 17-9.

7 Vasconcelos. Carolina Michaelis. Cancionciro da Ajuda. Ed. crit. coment. Halle, M. Nlemeser. 1904. 2 v. Abrevatura: CA(1). 
servil. A jogralia, palaciana ou popular, era, pois, oficio próprio do vilão.' Dai, a incompatibilidade, ao menos teórica, que na Península Ibérica havia entre a condição nobre e a profissão jogralesca.

\section{Lourenço era jogral impertinente}

No começo de sua carreira artística, Lourenço esteve, como jogral, a serviço do segrel João Garcia de Guilhade. Aprendeu, pois, em boa escola os segredos da gaia ciência, tornando-se, com o passar dos anos, o melhor dos jograispoetas. Suas composições atestam que não lhe faltava certa dose de talento poético. ${ }^{9}$ Leia-se, por exemplo, a cantiga d'amigo CV 866. Nessa graciosa cantiga de cantiga, o leve movimento circular das variantes formais em torno ao refräo atinge o optimum do processo paralelístico - a simetria de repetições e de variaçōes:

"Ua moça namorada

dizia un cantar d'amor.

E diss'ela: "Nostro Senhor,

hoj'eu foss'aventurada

que oíss'o meu amigo

com'eu este cantar digo!"

A moça ben parecia.

e en sa voz manselia *

cantou e diss'a menia:

"Prouguess'a Santa Maria

que oíss'o meu amigo

com'eu este cantar digo!"

Cantava mui de coraçon

e mui fremosa estava.

$\mathrm{E}$ disse, quando cantava:

"Peç'eu a Deus por pediçon

qu'oíss'o meu amigo

com'eu este cantar digo!"

Cônscio de suas qualidades versificatórias, Lourenço procura elevar-se, a todo o custo, à posição de trovador, para fazer da sua arte um meio de mantença e glória. Mas seu ta-

8 Vilăo (do latim Villanu, "referente so campo", que, por sua vez, é derivado de villa. "casa de campo") era o plebeu da Idade Médta; gente de balxa extracăo, "arraia miúda", no dizer de Fernăo Lopes. Na degeneracăo do seu sentido patentela-se a Influència de vil (latim vile), "baixo, grosseiro, ignóbil", cujo aumentativo acabou por zerar uma colisảo homonímica.

9 Eugênfo Asensio diverge um pouco de nossa opinião: "As cantigas de Lourenco revelam claramente as virtudes $e$ as limitaçoes do estilo velho, bom para a efusso passional, mas acanhado para uma senstbilidade complexa e educada" (p. 98).

- o macron (-) equivale so til. 
lento e suas impertinências chamaram a atenção dos trovadores de nobre estirpe, que, não podendo ver de bons olhos que um simples vilão como Lourenço se alçasse ao mais elevado grau da hierarquia artística, tacham-no de incompetente, não só no trovar a que agora se entregava, mas também no antigo ofício de citolar e cantar.

A tenção LAPA 219 mostra-nos Lourenço ainda sob a dependência de Guilhade, mas, ao mesmo tempo, já preludia a progressiva independência do jogral que, embora consciente de suas aptidões poéticas, ainda está à procura de um patrão mais generoso. ${ }^{10} \mathrm{Já}$ em outra tenção, LAPA 918, aparece a primeira manifestação de veleidades poéticas do jogral motivo da agressão verbal por parte de Guilhade, que ameaça até ir às vias de fato. Afirma Guilhade:

"Lourenço jograr, hás mui gran sabor

de citolares; ar queres cantar;

des i ar filha-te log'a trobar

e tees-t'ora já por trobador.

E por tod'est'ua ren ti direi:

Deus me cofonda, se hoj'eu i sei

destes mesteres qual fazes melhor!"

Retruca Lourenço:

"Joan Garcia, no vosso trobar

acharedes muito que correger;

e leixade-mi, que sei ben fazer

estes mesteres que fui começar;

ca no vosso trobar, sei-m'eu com'é,

i há de correger, per bōa fé,

mais que nos meus, en que m'ides travar!"

E conclui Guilhade:

“Vêes, Lourenç', ora m'assanharei, pois mal i entenças, e ti farei

o citolon na cabeca quebrar!"

D. João Soares Coelho e João Garcia de Guilhade andavam às turras. Parece que a discriminação social não favorecia a amizade entre o rico-homem e o cavaleiro-vilão. $\mathrm{Na}$ tenção com Lourenço, o trovador aproveita esplendidamente da ocasião para insinuar que Guilhade desconhecia a técnica

10 A abreviatura LAPA refcre-se à obra de LAPA, M. Rodrlgues. Cantigas d'escarhno 0 maldizer dos trovadores galego-portugueses. 2.ed. Colmbra. Ed. Galáxla, 1970. As lelturas, em parte, săo nossas. 
versificatória: não sabia rimar nem medir os versos (LAPA 240). Mas João Garcia não se dá por achado e, por ocasião do escândalo das amas e tecedeiras, revida ao poderoso fidalgo de Afonso III de Portugal. Andando pela corte do Rei Sábio, Soares Coelho pôs-se um dia a galantear certa ama com prendas de tecedeira. Alvoroçou-se o mundo trovadoresco com essa inovaçāo. Realmente, requestar mulheres casadas de baixo nivel social, embora pastorinhas (jovens), não se coadunava com a concepçāo do amor virginal das cantigas d'amigo, em que a mocelinha era a figura central, como também se opunha frontalmente à doutrina do amar altament cos cantares d'amor, nos quais o trovador devia erguer seus olhos súplices para donas de alta linhagem. D. Fornão Garcia Esgaravunha, D. Airas Peres Vuitoron e o jogral Juiāo Eolseiro não poupam remoques ao rico-homem trovador. João Garcia de Guilhade também entrou na liça com a cantiga de maldizer "Par Deus, Lourenço, muito desaguisadas" (LAPA 215). Usa o método indireto, já adotado por Soares Coelho. Manda que Lourenço dê este recado ao antagonista: João Garcia sempre decantou bōas donas e lhe causam estranheza aqueles que se preocupam em cantar amas mamadas (amas-de-leite). A composição, ainda que fraca, encerra, contudo, algum valor histórico. Carolina Michaëlis assinala o ano de 1273 para a inovação temática de Coelho. " Evidentemente, a mesma data deverá valer também para esse escárnio de Guilhade, que apresenta Lourenço ainda a serviço do segrel, mas já poeta autônomo e não mero executor. Portanto, 1273 marcaria o término a quo das atividades poéticas do jogral.

Infere-se de duas cantigas de maldizer que Lourenço largou o ofício de músico-cantor, abandonando de vez o serviço de Joāo Garcia de Guilhade, para lançar-se decididamente ao mester de trobar. Essa sua atitude, porém, não foi do agrado do sestroso ex-patrão, que, ferido em seu orgulho artístico, pois o jogral afirmara ter encontrado muitas falhas técnicas nas poesias do segrel, vale-se da ironia e do sarcasmo para molestá-lo:
"Lourenço, pois te quitas de rascar
e desemparas o teu citolon, rogo-te que nunca digas meu son, e jamais nunca mi farás pesar; ca per trobar queres já quarecer, e faräs-m'ora desejos perder do trobador que trobou do Juncal" (LAPA 210).

11 VASCONCELOS. Carolina Michaelis. Randg!assen zur altnortuglesichen Llederbuch: der Ammen-Strclt. Zeitschrift für romanische Philologie, 20(2):174-9. 1896. 


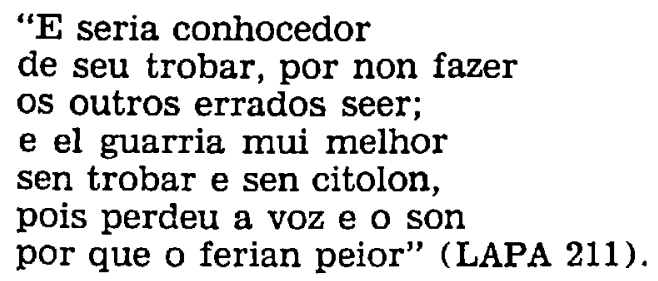

Os termos de cunino depreciativo rascar, cepo e citolon, para designar, respectivamente, o modo de executar e o instrumento musical, bem demonstram o desprezo que Guilhade votava às qualidades artisticas do jogral.

Mais tarde, Lourenço põe-se a entençar com D. João Peres de Aboim. As acusaçōes que Aboim move contra o jogral são as mesmas que, com monótona uniformidade, os outros trovadores assacam contra ele, tornando-se tópoi obrigató. rios: enquanto ficava a arranhar o seu citolon, Lourenço podia viver relativamente bem, mas quando tenta exorbitar os limites impostos pelas barreiras sociais e quer alçar-se a trovador, apenas patenteia toda a sua ressupina ignorância:

"Ben tanto sabes tu que é trobar ben quanto sab'o asno de leer" (LAPA 222).

Apesar das diatribes iniciais, Aboim reconhece ao jogral certas capacidades musicais:

"Lourenço, soias tu guarecer como podias, per teu citolon, ou ben ou mal, non ti digu'eu de non" (LAPA 222).

O trovador extravasa, mais tarde, numa tenção com Soares Coelho, a sua incontida satisfação pela atitude insolitamente cautelosa de Lourenço: o temido jogral, tão inclinado às contendas, nāo mais ousou atacá-lo porque implicitamente reconhecia que ele, Aboim, era o melhor dos trovadores. Transcrevemos a estrofe pertinente ao caso, que Carolina Michaëlis erroneamente atribuiu a Coelho: ${ }^{12}$

“Joan Soares, non poss'eu estar que vos non diga o que vej'aqui: vejo Lourenço com muitos travar, pero non-no vejo travar en $\mathrm{mi}$; e ben sei eu porque aquesto faz: porque sab'el que, quant'en trobar jaz, que mi o sei todo e que x'é tod'en mi" (LAPA 223). 
A ambição impele Lourenço para o alto... Entrar ao serviço da corte era o ideal perseguido por todo jogral. Também Lourenço lutava por isso. Porém, o áulico Rodrigo Eanes Redondo procurava barrar-lhe o acesso ao palácio do rei de Portugal, afiançando-lhe que
"de tod'homen que entencudo for non haverá en teu cantar sabor nen cho colherán en casa del-rei (LAPA 273).

Lourenço, porém, está convicto de suas habilidades artisticas que o habilitam ao posto de jogral da corte:

"Rodrigu'Eanes, u meu cantar for,
non achará rei nen emperador
que o non colha mui ben, eu o sei" (LAPA 273).

Mas na tenção com Martim Moxa, em que se profliga a avareza e a ganância dos validos do rei, deduz-se que Lourenço assistiu na corte. O clérigo Moxa começa por perguntar ao jogral:

"Vós, que soedes en corte morar,
destes privados queria saber
se lhes há privança muit'a durar,
ca os non vejo tomar e pedir;
e o que lhes non quer dar ou servir
non pode ren con el-rei adubar" (LAPA 278).

E difícil estabelecer se essa tenção pertence ao periodo português ou castelhano das atividades poéticas de Lourenço, porquanto não se sabe se a rubrica que vem sotoposta à poesia - "Esta cantiga supra foi feita, em tempo de D. Afonso, a seus privados" - diz respeito a Afonso X de Castela, ou a Afonso III ou Afonso IV de Portugal.

De saída, deve-se convir que a composição não pertence ao periodo de Afonso IV (1325-1357), filho de D. Dinis, pois dificilmente a atividade poética de Lourenço se estendeu para além da morte do Rei Sábio, ocorrida em 1284; é preciso tomar ainda em consideração que Sancho IV (1284-1295), rei de Leão e Castela, mostrou-se pouco propenso a continuar o mecenatismo paterno. Além disso, é inverossimel que Moxa ainda vivesse em 1325, pois o jogral Afonso Gomes de Sarria, que poetou nos últimos anos de Sancho II (1223-1248) e nos primeiros de Afonso III (1248-1279), já o tachava zombeteiramente de muito velho (LAPA 55). 
Só entram, portanto, em questão as cortes de Afonso $\mathrm{X}$ de Castela e Afonso III de Portugal. Qual das duas porém? Pelas insinuações de Joāo Vasques sobre a "fuga" de Lourenço e particularmente pela possibilidade de reconhecer os privados satirizados, os poderosos ministros do Bolanhês, estamos inclinados a pensar que se deva tratar da corte lusitana. De fato, pode-se identificar, pelo menos, dois prepotentes fidalgos de Afonso III: João Peres de Aboim e Estêvão Anes, que, acobertados pela aquiescência e até pelo apoio real, cometiam tamanhas rapinagens que bem mereciam essa critica causticante. ${ }^{13}$

Entretanto, Luciana Stegagno Picchio't julga que a sátira se refere aos ministros de Afonso $X$ e que, portanto, ela deve ser incluida entre os lamentos de Moxa sobre "o mundo às avessas", provocados pela situação que se criou no r:ino de Castela após a guerra de Granada (1263-1264) e a rebelião dos nobres (1271). Aliás, Tavani deixou aberta a estrada para essa solução:

“.. la tenzone con Martin Moxa, assegnata da C. Michaëlis al periodo portoghese e anzi assunta come prova della permanenza di Lourenço alla corte di Afonso III, può attribuirsi con altrettanta verosimiglianza al periodo castigliano, tanto sono vaghi e polivalente gli acceni allo strapotere e alla prepotenza dei favoriti reali." 15

Seja como for, Lourenço permaneceu por pouco tempo "en cas del-rei." A sua tenção com Joāo Vasques atesta que o jogral se encontrava, à época, fora de Portugal:

$$
\begin{aligned}
& \text { "- Lourenço, ..................... } \\
& \text { mais di-me ti, que trobas desigual; } \\
& \text { se te deitan por én de Portugal, } \\
& \text { ou mataste homen ou roubaste haver? } \\
& \text { "- Joan Vaásquez, nunca roubei ren, } \\
& \text { nen matei homen nen ar mereci } \\
& \text { por que mi deitassen, mas vii aqui } \\
& \text { por gãar algo .............. (LAPA 275). }
\end{aligned}
$$

Das duas frases "se te deitan por én de Portugal" e "vii aqui gāar algo" infere-se que o encontro realizou-se fora da pá-

13 Cr. TAVani, Gluseppe. Lourenço: poesio a tenzeni. Modera. Socleté Editric s Modenese, 1964. D. 127-8.

14 Cr. Martin Moya: le poesie. Romn. Ed.dcll'Atenco, 1968. D. 41-8 e 112-44.

15 TAVANI, p. 22-3. 
tria, provavelmente na corte de Afonso $\mathrm{X}$ - verdadeira academia de sábios e artistas. Qual teria sido, porém, o motivo real da "fuga" de Lourenço? Uma violenta reação dos privados de Afonso III que foram achincalhados na tenção com Martim Moxa, ou as restriçōes de ordem financeira impostos à corte portuguesa pelo novo Regimento de 1261 - "el rei haja três jograres en sa casa e non mais" - seriam motivos mais que suficientes. $\mathbf{E}$ as alusões de João Vasques serão elas, então, de cunho puramente polêmico-satírico? Infelizmente, não temos elementos para responder.

Em Castela, o ex-tocador de citola continuou a fazer tençōes, gênero em que se dizia mestre, o que, aliás, era pura verdade. Entretanto, agastado pelos contínuos ataques que os trovadores lançavam a seus dotes poéticos, recorreu a um poeta de nomeada, Pero Garcia Burgalês, na esperança de receber dele um julgamento sereno e objetivo, que the servisse, vitima de tantas acusaçōes, como arma de defesa. Não recebeu, porém, um juizo favorável:

"Don Lourenço, muito me cometedes

e en trobar muito ar loades;

e dizen esses con que vós trobades que de trobar nulha ren non sabedes, nen rimades nen sabedes iguar;

e pois vos assi travan en trobar, de vos julgar, senhor, non me coitedes" (LAPA 274).

Em resposta, Lourenço conclui seu desafio com três versos incisivos e bem estruturados, acusando o interlocutor de incompetência e, quiçá, de suborno:

"Don Pedro, en como vos ouç'i falar, ou vós ben non sabedes juigar, ou já dos outros of reçon havedes" (LAPA 274).

Polemizou, ainda, com Pedro Amigo de Sevilha, acusando o clérigo-jogral de produzir "cantares sempre en seu son", isto é, monotonas. Replicando, Pedro Amigo aconselha a Louren. ço que largue de compor cantigas e deixe de cantar e tanger o citolão (LAPA 272 e 230 ).

Apesar de tudo isso, o ex-jogral, ao que parece, viveu famoso e próspero na corte castelhana, chegando até a adquirir umas casas, embora sem muita sorte, como se depreende de um escárnio de Pero Gomes Barroso, fidalgo português a serviço do Rei Sábio: 


\author{
"Pero Lourenço ", comprastes \\ uas casas e mercastes \\ delas mal, pero catastes \\ ant'as casas e, porén, \\ par Deus, vós vos enganastes, \\ que as non catastes ben" (LAPA 389).
}

Interessante observar que, embora motejando, Barroso dispensa a Lourenço um tratamento cortês e respeitoso, usando o tratamento vós - indice, sem dúvida, de uma melhor posição social e econômica que o jogral logrou atingir.

\title{
Conclusão
}

Ao analisar o cancioneiro escarninho galego-português, entrevemos a convivência de trovadores, segréis e jograis, numa espécie de confraria lítero-musical, que gravitava em torno da corte do soberano ou dos paços senhoriais. Mas, embora congregados pelo mesmo objetivo: proporcionar entretenimento aos fidalgos, havia entre as classes trovadorescas das cortes e solares certo clima de tensões e conflitos, provocado pelas pretensões de artistas de origem vilã que queriam alçar-se à nobre categoria dos trovadores. Diante do fato incontrolável de certa ascensão social por parte de jograis talentosos, os produtores da arte privilegiados, estribados na cosmovisão hierarquizada da sociedade medieval e impelidos pelo temor da concorrência, não se cansavam de dirigir pesadas diatribes aos autores de origem mais humilde, para rebaixá-los ainda mais. Em contrapartida, respaldados em seu talento e na liberdade que o convívio com cortesãos lhes outorgava, os jograis não tinham receio de, contra-atacando, motejar ferina e ousadamente dos artistas de elevada progênie.

Para Kenneth Scholberg, a quase totalidade das tenções e dos cantares escarninhos cujo tema é a rivalidade entre trovadores e jograis não passa de pretexto lúdico para entreter e divertir. ${ }^{17}$ Sem dúvida, sob a ótica da fidalguia, as ironias e as invectivas que os trovadores dirigiam às pretensões trovadorescas do jogral Lourenço, consideradas desca. bidas e ridículas porque contrárias à estratificação social da época, não passavam de um jogo de palavras, um belo passo

16 Lourchço, ao que parcec, tinha mals um prenome: Pero. Estamos inclinados a ver no Pero que Inicta a estrofe acima transcrita nao uma conjunçao, mas sim. um nome próprio. Essa nos.5a opinia vem corroborada pelo manuscrito, que, enquanto abrevir o segundo pero (po) do verso 3. transcreve integralmente esta primeira lorma, - que tanibim necutece na lença do jocral com D. Soares Coelho: “Pero Lourenco, pero t'eu ofa/tencon desigual e que non rimava,/ pero qu'essa entençon de t! falava'. (LAPA 240).

17 Sátira e invectiva en la España medieval. Madrld. Gredos, 1971. p. 80. 
de esgrima, como se diria hoje em dia. Para Lourenço, porém, essa confrontaçāo era algo muito sério: constituia uma autodefesa, com propósitos de ascensão social. Não há negar que os violentos ataques da parte de poetas de alta prosápia e os revides, não menos causticantes, de Lourenço revelam as relaçōes verticais existentes na sociedade da época e traduzem certas tensões entre as classes do trovadorismo.

Apesar dos protestos teóricos dos trovadores, Lourenço, ex-tocador de citola, conseguiu atingir, por seu talento e por sua pertinácia e impertinència, posição de relevo na vida artística do seu tempo. A quantidade de composições, treze ao todo, que especificamente tratam dos mesteres jogralescos de Lourenço e de suas pretensōes a trovador, comprova a popularidade que ele devia gozar nas cortes peninsulares do século XIII.

Rodrigues Lapa alude várias vezes aos princípios "democráticos" da civilização trovadoresca, afirmando a existência de uma quase nivelação entre nobres, cavaleiros-vilãos e peões. ${ }^{18} \mathrm{Na}$ verdade, essa colaboração sul generis entre poetasmúsicos, fidalgos e plebeus - quem sabe, forçada às vezes - constitui um dos grandes méritos do trovadorismo galegoportuguês.

\section{RESUME}

Lauter cherche à préciser les attributions et la condition du jongleur dans la société hiérarchisée de la Péninsule Ibérique au XIII siècle. Le jongleur est le professionnel qui vit de son métier: citolar et dizer sões d'autrui. C'cst un homme, donc, qui appartient à la classe servile. La jonglerie courtoise ou populaire était un office propre au vilain, d'où l'incompatibilité - du moins théorique qu'il y avait, dans la Péninsule, entre la condition de noble et la profession de jongleur. Quoique rassemblées par le même but - celui d'offrir des divertissements aux nobles -, les classes de troubadour, des cours et dcs manoirs seigneuriaux, étaient soumises à un certain climat de tensions et conflits, du au fait incontrōlable de l'ascension sociale des jongleurs talentueux, habiles dans l'art de trobar.

Malgré son origine humble, Lourenço est devenu te meilleur des jongleurs-poètes. Mais son talent et son ambition ont attiré l'attention des troubadours de lignée, qui se moquaient de ses prétentions à troubadour, en le considérant incompétent. En revanche, Lourenço, tencista fécond, 
a répliqué bravement aux attaques de part des artistes de lignage relevé.

Prototype du jongleur à prétention à troubadour, Lourenço arriva à atteindre une position de relief dans le troubadourisme luso-galicien, gràce a ses qualités artistiques, à son obstination et à son impertinence.

\section{REFERENCIAS BIBLIOGRAFICAS}

1 ADRAGAO, José V. Cantigas de escárnio e maldizer: uma leitura sociolinguística. Comunicação apresentada ao XV Congresso Internacional de Linglística e Filologia Românicas, Rio de Janeiro, 1977. Datilografado.

2 ASENSIO, Eugênio. Poética y realidad en el cancionero peninsular de la Edad Media. 2. ed. Madrid, Gredos, 1970.

3 LACERDA, Virginia C. de. Unidades literárias. Rio de Janeiro, Org. Simōes, 1953.

4 LAPA, M. Rodrigues. Cantigas d'escarnho e de maldizer dos cancioneiros medievais galego-portugueses. 2. ed. Coimbra, Ed. Galá. xia, 1970.

5 - Liçōes de literatura portuguesa. Época medieval. 7. ed. Coimbra, Coimbra Ed., 1970.

6 MENENDEZ PIDAL, Ramón. Poesia juglaresca y juglares. Buenos Aires, Espasa-Calpe, 1942.

7 NUNES, José Joaquim. Cantigas d'amigo dos trovadores galego-por. tugueses. Coimbra, Impr. Universidade de Coimbra, 1928. v. 1.

8 PICCHIO, Luciana Stegagno. Martin Moya: Ie poesie. Roma, Ed. dell'Ateneo, 1968.

9 Saraiva, antónio J. História da cultura em Portugal. Lisboa, Jor. nal do Foro, 1950 . v. 1.

10 SCHOLBERG, Kenneth R. Sútira e Invectlva en la España medieval. Madrid, Gredos, 1971.

11 TAVANI, Giuseppe. Lourenço: poesie e tenzoni. Modena, Societa Editrice Modenese, 1964.

12 VASCONCELOS, Carolina Michaëlis. Cancioneiro da Ajuda. Ed. crít. coment. Halle, M. Niemeyer, 1904. 2 v.

13 - Randglossen zur altportugiesichen Liederbuch: der Ammen-Streit. Zeitschrift für romanische Phllologie, 20(2):145218,1896 . 